\section{Things We Haven't Seen}

Conscious of the danger inherent in throwing stones when one's own house is glass, let's start with a debacle that shaped this author's attitude toward the discovery process thereafter.

I could see fame, if not fortune, well within my grasp one evening as I tended an experiment for a more senior graduate student. What a stroke of luck that such an observation, running counter to all accepted theories of nuclear physics, should occur during my watch! We were measuring the angular correlation of gamma radiation emitted in time-coincidence from a radioactive source which decayed through a gamma-gamma cascade. The intermediate state of that cascade, according to the literature, had a lifetime too short to resolve with our electronics-the data being a single, narrow peak (the instrumental resolution) in a time-spectrum collected in a multichannel analyzer.

Earlier in the day, it had been necessary to change a photomultiplier tube and remount the sodium iodide scintillator crystal (in those days, integral-line detectors were not so common) before starting a new run. This was a routine procedure which I had seen done many times before. As the night wore on, I began to see a degradation in time-resolution which grew over several hours into a pronounced exponential tail on one side (the second gamma side) of the formerly narrow peak. After checking every conceivable source of electronic problems and finding everything in order, I concluded we had a nuclear lifetime that had mysteriously begun to lengthen with time-an unheard of and clearly exciting new phenomenon.

Well, the new day brought more than sunlight into the lab. It brought my recently adopted thesis adviser, who, I thought, epitomized unreasonable skepticism. Whereas I would have been delighted if he had called the university public affairs office to dictate a press release, he instead dropped in a calibration source (cobalt-60, I believe), and to my chagrin, this isotope too had a revised nuclear lifetime.

I learned two important lessons from this experience. First, never use too much optical-coupling grease when mounting a scintillator on a photomultiplier-gravity may gradually decouple your light path and degrade your time-resolution. Second, a healthy dose of skepticism in the face of new revelations is most appropriate and can save one's face if not one's career.

Perhaps my typical educational experience carries a less obvious message. A time-dependent nuclear lifetime was not discovered, but that such a phenomenon cannot exist was also not proved. The null result does not prove that things we haven't seen do not exist, merely that we can't see them by the chosen means. This leaves the door open to hope that the hypothesized phenomenon, invoked to explain the subsequently debunked observation and with which one has become quite enamored, may be rescued from iniquity.

For a moment in that graduate lab, I lost sight of what events triggered my attachment to my hypothesis and tried to conceive of a new way to prove it. The cobalt- 60 source provided a simple and mercifully quick squelch of the irrational attachment. More often than not, however, a longer, more convoluted process drawing in many dispersed investigators is required in such cases. That which incites us to wonder if the unproven really does exist is the crux of why we like science in the first place.

Fluctuations in the steady rate of scientific discovery normally encounter negative feedback, a restoring force, in the form of skeptical peer review which inoculates the process with a critical damping. Net advances, if any, are realized asymptotically after an initial transient. Self-damping seems not to be working nearly as effec- tively how as it did for me as a graduate student. The antibodies that are designed to seek out flukes and glitches invading the body scientific have been neutralized by a new virulent circumvention of peer review-i.e., the press release.

Legitimate flukes (those where charlatanism is not suspected) of some years ago seemed to have been cured appropriately. "Polywater," an unexpected polymerization of $\mathrm{H}_{2} \mathrm{O}$ in normal pure water," came and went largely unnoticed by the public. Colored electrons ${ }^{2}$ (i.e., electrons that remembered the frequency of a laser field encountered in a dielectric through which they'd passed) also returned to iniquity without fanfare. Not so when a single track in a stack of Lexan $^{\text {TM }}$ plastic cosmic-ray detectors aboard a high altitude balloon over Sioux City, lowa in September 1973 was interpreted as having been made by the magnetic monopole hypothesized by Dirac. ${ }^{3}$ The New York Times informed us that a container of monopoles could pull a ship across oceans using the Earth's magnetic field. Later explained as a more mundane heavy element nucleus-the monopole disappeared-but the modern precedent of parallel publication in Phys. Rev. Letters and the New York Times had been set. Still, the events didn't seem to stimulate much public attention.

A rather recent fluctuation in public credibility in the biomedical field was the solvent-memory phenomenon wherein an infinitely diluted antibody solution still showed beneficial effect as if the solvent was altered by its former solute. "Almost as much controversy embroiled the publication process as the technical report itself. Debunking the positive result leaves the more gullible among us clinging to the unsubstantiated explanation left behind.

The obvious next allusion should be to the most recent public credibility fluctuation over so-called cold fusion. Media attention to this purported panacea seems far greater than past departures from propriety. Why? Perhaps because of the groundwork laid by the one blatant counterexample not yet mentioned.

High temperature ceramic oxide superconductors survived the skeptics, were reproduced in hundreds of labs, and thus backhandedly justified early press involvement. Now there is a greater license to subvert the built-in restoring force. $\mathrm{HiT}_{\mathrm{c}}$ is indeed a breakthrough, but don't forget reports of $150 \mathrm{~K}, 240 \mathrm{~K}$ and higher transition temperatures based on inadequately documented experiments which hit the front pages and have not been reproduced. Not content with $\sim 125 \mathrm{~K}$, whetted appetites cling to the hope that higher values will be found. We can't prove that materials with that property can't exist. Time will tell.

We can construct a very long list of things we haven't seen. The next step in the trend toward uncritical science may be to dispense with the fluke that hints at the yet-to-be-discovered and simply generate press releases based on our list. After all, this is the stuff of which science fiction is made.

\section{E.N. KAUFMANN}

1. B.V. Derjaguin and N.V. Churayev, J. Colloid Intert. Sci. 36 (1971) p. 415. B.V. Derjaguin, Discussions of the Faraday Society 42 (1966) p. 109. L.C. Allen and P.A. Kollman, J. Colloid. Interf. Sci. 36 (1971) p. 461 and Nature 223 (1971) p. 550.

2. H. Schwarz and H. Hora, Appl. Phys. Lett. 15 (1969) p. 349.

3. P.B. Price et al., Phys. Rev. Lett. 35 (1975) p. 487.

4. E. Davenas et al., Nature 333 (1988) p. 816. 